\title{
The arginine regulon of Escherichia coli: whole- system transcriptome analysis discovers new genes and provides an integrated view of arginine regulation
}

\author{
Marina Caldara, Daniel Charlier and Raymond Cunin \\ Laboratorium voor Erfelijkheidsleer en Microbiologie, Vrije Universiteit Brussel, Pleinlaan 2, \\ 1050 Brussels, Belgium
}

\begin{abstract}
Correspondence
Raymond Cunin

rcunin@vub.ac.be
\end{abstract}

Received 24 April 2006

Revised 20 July 2006

Accepted 28 July 2006

\begin{abstract}
Analysis of the response to arginine of the Escherichia coli K-12 transcriptome by microarray hybridization and real-time quantitative PCR provides the first coherent quantitative picture of the ArgR-mediated repression of arginine biosynthesis and uptake genes. Transcriptional repression was shown to be the major control mechanism of the biosynthetic genes, leaving only limited room for additional transcriptional or post-transcriptional regulation. The art genes, encoding the specific arginine uptake system, are subject to ArgR-mediated repression, with strong repression of artJ, encoding the periplasmic binding protein of the system. The hisJQMP genes of the histidine transporter (part of the lysine-arginine-ornithine uptake system) were discovered to be a part of the arginine regulon. Analysis of their control region with reporter gene fusions and electrophoretic mobility shift in the presence of pure ArgR repressor showed the involvement in repression of the ArgR protein and an ARG box 120 bp upstream of hisJ. No repression of the genes of the third uptake system, arginine-ornithine, was observed. Finally, comparison of the time course of arginine repression of gene transcription with the evolution of the specific activities of the cognate enzymes showed that while full genetic repression was achieved 2 min after arginine addition, enzyme concentrations were diluted at the rate of cell division. This emphasizes the importance of feedback inhibition of the first enzymic step in the pathway in controlling the metabolic flow through biosynthesis in the period following the onset of repression.
\end{abstract}

\section{INTRODUCTION}

The term regulon was coined by Maas \& Clark (1964) to describe the genetic and regulatory organization of the genes of arginine biosynthesis in Escherichia coli. The arg genes are not organized into one single operon, in contrast to what was observed at that time for several other pathways, but they are scattered over different chromosomal loci. Their expression is repressed by arginine to different extents, but in a coordinated fashion through the action of the arginine repressor ArgR. The regulon type of organization allows differential repression of genes or groups of genes within one metabolic way, as well as multiple regulation of individual genes - cumulative or cross-pathways regulation. Since then, regulons have been found to be widespread in E. coli

Abbreviations: CP, carbamoyl phosphate; CPSase, carbamoyl-phosphate synthase; NAGSase, N-acetylglutamate synthase; OTCase, ornithine transcarbamylase; RTq-PCR, real-time quantitative PCR.

Complete microarray data have been deposited at the NCBI Gene Expression Omnibus (www.ncbi.nlm.nih.gov/projects/geo/index.cgi) with the accession number GSE4724. and in other micro-organisms. The molecular basis for differential repression of arginine genes is the interaction of a unique complex of aporepressor (ArgR)/co-repressor (arginine) with operator loci differing in base composition, number and localization with respect to the promoter of conserved 18 bp elements called ARG boxes (Cunin et al., 1983; Charlier et al., 1992; Charlier \& Glansdorff, 2004). The cis- and trans-acting elements of this regulatory mechanism are remarkably well conserved through the bacterial domain (Charlier, 2004).

Arginine is synthesized in eight enzymic steps, starting from glutamate. The synthesis of carbamyl phosphate, a metabolite common to arginine and pyrimidine biosynthesis, is regulated jointly by arginine and pyrimidines through transcriptional repression of a tandem pair of promoters and allosteric control of carbamoyl-phosphate synthase (CPSase) activity (Piérard et al., 1965; Piette et al., 1984; Devroede et al., 2004). Although information on genes, enzymes and regulation of the arginine regulon is substantial (for reviews, see Cunin et al., 1986; Charlier \& Glansdorff, 2004), it is incomplete and, as it was obtained by different teams using different approaches often dealing with specific 
limited objectives, it does not always lend itself to integration into a coherent description of the system.

As a prerequisite to the development of a mathematical model of arginine biosynthesis, including its dynamics, it is necessary to identify all the components of the arginine regulon and to investigate their regulation, using a global approach to obtain a set of coherent values for key parameters of the system. The response to arginine of mRNA expression profiles was analysed using hybridization to chromosomal DNA microarrays and real-time quantitative $(\mathrm{RTq}) \mathrm{PCR}$, to obtain derepression/repression ratios for the transcription of individual genes and/or operons, including those for which such information was lacking, and to discover potential new members of the regulon on the basis of their expression profile. For such newly identified genes, the presence and functionality of ARG boxes was investigated.

In addition to biosynthetic genes, this analysis has revealed which other genes, e.g. arginine uptake genes, are subject to specific regulation by arginine, thus identifying them as components of the regulon.

Another important point, pertaining to the dynamics of the regulon, is the time response of its constituents to changes in the environment. The time course of repression by arginine was monitored by RTq-PCR for a representative set of genes, including newly discovered members of the regulon, and by parallel assays of selected enzymic activities.

\section{METHODS}

Chemicals. L-Methionine, L-arginine, L-ornithine, carbamoyl phosphate (CP) (dilithium salt), magnesium chloride, potassium chloride, boric acid, ATP, DTT, chloramphenicol, kanamycin and streptomycin were purchased from Sigma. Glucose, glycerol, sodium hydroxide, ammonium sulfate and calcium chloride were purchased from Merck. Tris base was purchased from Invitrogen, sodium bicarbonate from UCB and polyacrylamide from Severn Biotech. Sodium $\left[{ }^{14} \mathrm{C}\right]$ bicarbonate and $\left[{ }^{32} \mathrm{P}\right] \mathrm{ATP}$ were obtained from Amersham Biosciences.

Strains and growth conditions. $\mathrm{P} 4 \mathrm{X}(\mathrm{Hfr}$, met $B$ ) and its genetically derepressed derivative strain $\mathrm{P} 4 \mathrm{XB} 2(\mathrm{Hfr}, \operatorname{metB} \operatorname{argR}$ ) were used in this study. P4X is a derivative of E. coli $\mathrm{K}-12$, through $58-161$ and W6 (Bachmann, 1987), and it is the strain in which previous studies of arginine synthesis were performed by this laboratory. It has been designated wild-type for arginine synthesis. Cells used for expression analysis were grown in minimal medium (Glansdorff, 1965) supplemented with $0.5 \%(\mathrm{w} / \mathrm{v})$ glucose, L-methionine $\left(100 \mu \mathrm{g} \mathrm{ml}^{-1}\right)$ and, when specified, with L-arginine $\left(100 \mu \mathrm{g} \mathrm{ml}^{-1}\right)$. Repression studies of hisJQMP with lacZ fusions used strains CSH100, FW102 (Whipple, 1998) and FW102 $\operatorname{argR}(\mathrm{Xu}$ et al., 2003) grown on rich medium (Glansdorff, 1965) or on minimal medium in the presence of appropriate antibiotics (kanamycin, $100 \mu \mathrm{g} \mathrm{ml}^{-1}$; streptomycin, $25 \mu \mathrm{g} \mathrm{ml}^{-1}$; chloramphenicol, $25 \mu \mathrm{g} \mathrm{ml}^{-1}$ ).

For transcription profile analysis, cells were grown in a rotary shaker at $37^{\circ} \mathrm{C}$ and harvested by centrifugation at mid-exponential phase $\left(\mathrm{OD}_{660}=0 \cdot 5\right)$ before quenching their metabolism in liquid nitrogen. No RNA-protecting agent was used in this standard procedure. However, to verify that cold shock and other stresses related to the sampling procedure did not affect expression profiles through transcriptional induction or RNA degradation, RNAprotect (Qiagen) was added to 'freeze' transcriptional profiles in a series of samples prior to centrifugation, and extraction was performed in parallel with that of unprotected samples. The expression profiles of a representative set of genes $(\arg A, \arg C, \arg D, \operatorname{art} J$, hisJ and $\operatorname{argR})$ were compared between protected and unprotected samples using $\mathrm{RTq}$ PCR. The difference, when observed, was below or about the SD, showing that profiles are not modified during sampling and extraction. For these genes, derepression/repression ratios obtained by both procedures are shown in Table 4.

For the time course of arginine repression, the wild-type was cultivated in a Biostat C (Braun Biotech International) in 51 minimal medium. The medium was sterilized in situ at $119^{\circ} \mathrm{C}$. Glucose was autoclaved separately. The fermenter was inoculated with $200 \mathrm{ml}$ of an exponentially growing culture. The fermentation was run at $37^{\circ} \mathrm{C}$ with stirring (300 r.p.m.) and at $\mathrm{pH}$ 7. When the cell population reached mid-exponential phase, arginine was added and a dilution rate of $0.65 \mathrm{~h}^{-1}$ was imposed. Samples for the determination of enzymic activities were collected by centrifugation at $4{ }^{\circ} \mathrm{C}$ and stored at $-20^{\circ} \mathrm{C}$ until required.

RNA isolation. Total RNA was isolated using the RNeasy RNA isolation kit, according to the manufacturer's specifications (Qiagen), and stored in RNase-free water at $-80^{\circ} \mathrm{C}$. RNA concentration was determined by UV spectrometry and its quality was controlled by agarose gel electrophoresis.

Microarray analysis and data processing. The GeneChip E. coli Genome 2.0 Array (Affymetrix) was used.

After UV spectrometry and agarose gel electrophoresis checks, total RNA was further controlled for integrity and purity using a Bioanalyser 2100 (Agilent) and a Nanodrop spectrophotometer. Total RNA $(10 \mu \mathrm{g})$ showing no signs of degradation or impurities, was supplemented with poly-A RNA controls and reverse transcribed to cDNA using random primers. After RNA degradation with $\mathrm{NaOH}$, cDNA was purified (MinElute PCR Purification Kit; Qiagen), analysed for yield $(30-120 \mu \mathrm{g})$ and purity $(260 / 280 \mathrm{~nm}$ and $260 / 230 \mathrm{~nm}$ absorption ratios $>1 \cdot 8$ ), then fragmented using DNase I (Amersham Pharmacia Biosciences) and labelled terminally with biotinylated GeneChip DNA Labelling Reagent (Affymetrix). A minimum of $1 \mu \mathrm{g}$ fragmented probe was resuspended in $80 \mu \mathrm{l}$ hybridization buffer containing $3 \mathrm{nM}$ control oligo B2 (Affymetrix). Hybridization was performed in a rotisserie oven at $45^{\circ} \mathrm{C}$ for $16 \mathrm{~h}$. The chips were washed and stained in a GeneChip Fluidics Station 400 (Affymetrix) and subsequently scanned with the GeneChip Scanner 3000 (Affymetrix). Initial data analysis was performed using GeneChip Operating Software. Microarray quality control parameters were as follows: noise (RawQ) less than 5, background signal less than 40 (100 target intensity for array scaling), consistent numbers of genes detected as present across arrays.

Data were processed using the robust multiarray average algorithm (RMA) for normalization, background correction and expression value calculation (Irizarry et al., 2003). Expression levels obtained by three independent replicates of every condition were compared using the Limma package of the Bioconductor software (Gentleman et al., 2004). The robustness of the data were further enhanced by Bayes adjustment and the $P$ values were corrected for the false discovery rate (Benjamini \& Hochberg, 1995).

RTq-PCR. First-strand cDNA was generated from $2 \mu \mathrm{g}$ RNA in a reaction $(20 \mu \mathrm{l}$ final vol.) using random hexamer primers and Superscript II reverse transcriptase (Invitrogen), followed by RNase $\mathrm{H}$ treatment (Fermentas). PCR reactions were prepared in a $25 \mu \mathrm{l}$ volume containing SYBR Green PCR Master Mix (Applied 
Biosystems), $0 \cdot 5 \mu \mathrm{cDNA}$ and $150 \mathrm{nM}$ each forward and reverse primer. Amplicon size was always between 100 and $250 \mathrm{bp}$. Amplification cycles were carried out in an iCycler IQ (Bio-Rad) using the following protocol: $95^{\circ} \mathrm{C}$ for $10 \mathrm{~min}, 40$ cycles of $15 \mathrm{~s}$ at $95^{\circ} \mathrm{C}, 30 \mathrm{~s}$ at $58^{\circ} \mathrm{C}$ and $30 \mathrm{~s}$ at $72^{\circ} \mathrm{C}$, followed by melting curve analysis.

All runs included a primer pair for the detection of the rpoS gene. This gene was chosen as internal reference because it showed exactly the same significant expression levels across the strains and the conditions used in the microarrays. It was previously reported that rpoS is poorly expressed during exponential growth (Jishage et al., 1996). However, in the conditions used, this was not observed: the expression level of rpoS was comparable to that of the other genes studied and, as expected from the microarray analysis, stable, in contrast to the expression of $r p o N$ or $g y r B$ which are frequently used as references. The relative expression ratios were calculated using the 'Delta-Delta Method' (Perkin Elmer). For each gene tested, the expression measured in the wild-type on unsupplemented minimal medium was chosen as the reference value $(100 \%)$. Forward $(\mathrm{Fw})$ and reverse $(\mathrm{Rv})$ primers are listed in Table 1.

Enzyme assays. Assays were performed on cellular extracts prepared as follows: cells were resuspended in a buffer containing $20 \mathrm{mM}$ Tris/ $\mathrm{HCl}(\mathrm{pH} 7 \cdot 5), 10 \mathrm{mM} \mathrm{MgCl}, 15 \%$ glycerol, $1 \mathrm{mM}$ DTT and complete protease inhibitors cocktail (Roche), sonicated for $4 \mathrm{~min}$ at $5{ }^{\circ} \mathrm{C}$ and dialysed for $2 \mathrm{~h}$ against the same extraction buffer at $4{ }^{\circ} \mathrm{C}$.

$\mathrm{N}$-Acetylglutamate synthase (NAGSase) was assayed according to Abadjieva et al. (2001), with the following modifications: prior to the assay, the extract was dialysed instead of being run on a Sephadex G-25 column and the reaction was incubated for $5 \mathrm{~min}$ at $37^{\circ} \mathrm{C}$.

Ornithine transcarbamylase (OTCase) activity was determined as described by Glansdorff \& Sand (1965). The samples were incubated for $15 \mathrm{~min}$ at $37^{\circ} \mathrm{C}$ in the presence of $2 \mathrm{mM}$ ornithine and $10 \mathrm{mM} \mathrm{CP}$ in $50 \mathrm{mM}$ Tris/ $\mathrm{HCl}, \mathrm{pH} 8$.

CPSase was assayed according to Simmons et al. (1999) with modifications. The reaction mixture contained $10 \mathrm{mM}$ bicarbonate, including $2 \mu \mathrm{Ci}(74 \mathrm{kBq})\left[{ }^{14} \mathrm{C}\right]$ bicarbonate, and $10 \mathrm{mM} \mathrm{ATP} / \mathrm{MgCl}_{2}$.
The reaction was started by the addition of $100 \mu$ cellular extract, allowed to proceed for $5 \mathrm{~min}$ at $37^{\circ} \mathrm{C}$ and terminated by adding $100 \mu \mathrm{l}$ $1 \mathrm{M}$ ammonium sulfate. Each experiment contained a control without glutamine. Protein concentrations were determined by the Lowry method.

Mobility shift electrophoresis. Mobility shift experiments were performed by the method of Fried \& Crothers (1983). ${ }^{32} \mathrm{P}$-labelled DNA fragments were prepared by PCR amplification with a pair of oligonucleotides, of which one was $5^{\prime}$-end-labelled with ${ }^{32} \mathrm{P}$, and purified by PAGE. Binding experiments were performed at $37^{\circ} \mathrm{C}$, by incubating different amounts of purified ArgR repressor protein and a constant amount of labelled DNA (15000 c.p.m.) in the presence of an excess of non-specific competitor DNA (sonicated calf thymus DNA). ArgR binding took place in $20 \mathrm{mM}$ Tris/ $\mathrm{HCl}, \mathrm{pH} 7 \cdot 4$, $500 \mathrm{mM} \mathrm{KCl}, 10 \mathrm{mM} \mathrm{MgCl} 2,1 \mathrm{mM}$ DTT, $20 \mathrm{mM}$ L-arginine and $5 \mathrm{mM} \mathrm{CaCl}_{2}$. Separation of free and bound DNA was performed on $5 \%$ polyacrylamide gels. Migration was for $3 \mathrm{~h}$ at $8 \mathrm{~V} \mathrm{~cm}^{-1}$ in arginine running buffer ( $89 \mathrm{mM}$ Tris, $89 \mathrm{mM}$ boric acid, $10 \mathrm{mM} \mathrm{MgCl}_{2}$ and $5 \mathrm{mM} \mathrm{L}$-arginine).

Assay of hisJaMP repression, using fusions with lacZ. To construct the wild-type hisJQMP promoter-lacZ reporter fusion (WT $\mathrm{p}_{\text {hisJQMP }}$ ), the complete promoter region was amplified by PCR as an EcoRI-BamHI fragment using the primers $\mathrm{MclFw}\left(5^{\prime}-\right.$ GGGAATTCTACGTCGCTGGGAAGCTG- $\left.3^{\prime}\right)$ and Mc2Rv (5'GG GGATCCAATGTCCTCAACTGACAGTC-3'), and cloned into the promoterless plasmid pFW11-null $\left(\mathrm{Km}^{\mathrm{r}} \mathrm{Cm}^{\mathrm{r}}\right)$ which contains the $3^{\prime}$ end of lacI and the $5^{\prime}$ end of lacZ. To knock out the identified ARG box, a $\mathrm{Km}^{\mathrm{r}}$ cassette was generated by PCR using primers with $50 \mathrm{nt}$ homology extensions and introduced in a P4X strain expressing the $\lambda$ Red recombinase. After selection, the resistance gene could be eliminated by using a helper plasmid expressing the FLP recombinase which acts on the FRT sites flanking the resistance gene as described by Datsenko \& Wanner (2000). The ARG box knock-out promoter region obtained was then cloned into the pFW11-null plasmid following the same procedure as for the wild-type promoter. Two truncated promoters were also generated by PCR. The first one, $\Delta 1 \mathrm{p}_{\text {hisJQMP }}$, was amplified starting from the ARG box using primer Mc3Fw (5'-GGGAATTCTTAATGAAAATAATACGTCTAAC- $3^{\prime}$ ) in combination with Mc2Rv. The second construct, $\Delta 2$

Table 1. List of primers used for RTq-PCR analysis of expression profiles

\begin{tabular}{|c|c|c|}
\hline Gene & Forward $\left(5^{\prime}-3^{\prime}\right)$ & Reverse $\left(5^{\prime}-3^{\prime}\right)$ \\
\hline rpos & ATCGCAGGGAGCCACACAGC & GGCGGCGAGAGGCGATC \\
\hline $\arg A$ & TGGAGCAGCAAGGTATTCTGGTAC & CGCAGGCAATAGTCGTGTTATCG \\
\hline $\arg C$ & TCGCCATCCGCATATGAACA & CGGCGCTAAATCGTGGCTAA \\
\hline $\arg D$ & GGCGAAACTCTGTGGCATAT & AACAGCGAGCGACCATGAA \\
\hline $\arg E$ & GAAGAGGCACTCGATCAAAG & TCCAGCGACCGTCATCAAAT \\
\hline $\operatorname{argF}$ & GGCGGATGTATG ACGGCATTC & GCTGGGTCGGGTGGAACTC \\
\hline $\operatorname{argI}$ & TTGCTGCGTGAATATCAGGTGAAC & TGACTTCCATACCGCCATGTAGG \\
\hline $\arg G$ & GGAGCGGTTCCTTATGCATA & СTCTCTGAATAGCGGCAATAC \\
\hline $\arg R$ & CGAAGCTCGGCTAAGCAAGA & AGTTCAGCTGGCAGGCAGTA \\
\hline $\operatorname{car} A$ & GGCAATGTCGGCACCAATGA & CGGCAATCGCCACGATGTTA \\
\hline $\operatorname{carB}$ & CACTTCCGACCGCCTCT ACTTC & GGTACGCCAGCAGCTTCCAG \\
\hline $\operatorname{artP}$ & CATCAGGCGCTGTTCGATAT & TGGTTGCCTGCAATGTTGAG \\
\hline artJ & AGCGTAGCAAACAGGTATCG & TTTCACTTCCGGGTGCTGAT \\
\hline hisJ & AGCGAAGAAGATTGACGCCA & CTGTCGGCTGAATGTCAGAA \\
\hline $\arg P$ & GGTGATACGTGAACGAGGAT & ССАСТСТTCTTCCAGCAACT \\
\hline $\arg T$ & TCTATTCCGATCTGGCTGCA & CGGTGCCATCACCTAAGTAT \\
\hline
\end{tabular}


$\mathrm{p}_{\text {hisJQMP }}$, starts downstream from the ARG box and was generated using primers $\mathrm{Mc} 4 \mathrm{Fw}$ (5'-GGGAATTCTAACGGGGCGGGATATTTG-3') and Mc2Rv.

The different plasmids were introduced into strain CSH100 $\left(\mathrm{Sm}^{\mathrm{s}}\right)$ which bears an $\mathrm{F}^{\prime}$ episome containing a truncated lac operon. The transfer of the cassette from pFW11 occurred via a double homologous recombination. Strain construction was completed upon conjugation with the FW102 recipient strain $\left(\mathrm{Sm}^{\mathrm{r}}\right)$ or its FW102 $\Delta \operatorname{argR}$ derivative, followed by screening for $\mathrm{Sm}^{\mathrm{r}} \mathrm{Km}^{\mathrm{r}} \mathrm{Cm}^{\mathrm{s}}$ transconjugants as described by Whipple (1998).

$\beta$-Galactosidase specific activity was assayed in cell-free extracts of cultures grown in minimal medium with or without arginine. Assays were performed as described by Miller (1972). Enzyme activities are

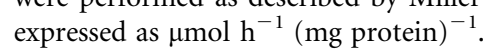

\section{RESULTS AND DISCUSSION}

\section{Transcriptome response to arginine}

Microarray hybridization experiments analysed expression patterns under three different conditions and/or backgrounds: wild-type (P4X) under full repression (extracellular arginine added), wild-type under partial repression (by intracellular arginine) and genetic derepression (P4XB2, an $\operatorname{argR}$ derivative of $\mathrm{P} 4 \mathrm{X}$, in the presence of arginine).
Expression levels obtained by three independent replicates of each experimental condition were compared. Results were considered significant if they showed a signal log ratio lower than -1 or higher than +1 , corresponding to a twofold decrease or increase of expression, respectively, with a $P$ value lower than $0 \cdot 05$. An ArgR-mediated effect (repression) is shown when the P4XB2 $(\arg )$ to $\mathrm{P} 4 \mathrm{X}(\arg )$ ratio is equal to or higher than the $\mathrm{P} 4 \mathrm{X}(\mathrm{min})$ to $\mathrm{P} 4 \mathrm{X}(\arg )$ ratio. To verify the microarray results, RTq-PCR was performed on at least one gene of each transcription unit identified by microarray analysis under the same set of conditions and also in triplicate.

A list of regulon genes and their cognate proteins - enzymes or binding proteins - is given in Table 2 .

\section{Derepression/repression ratios and identification of new genes of the regulon}

Genes of arginine biosynthesis. All the biosynthetic genes showed a significant derepression/repression ratio in microarray hybridization (Table 3). For $\arg A, \arg D$ and $\arg G$, these are the first transcriptional repression data ever obtained. E. coli K-12 possesses two genes encoding OTCase: $\operatorname{argI}$ and $\operatorname{argF}$ : for these too, the first transcriptional repression values were obtained.

Table 2. Arginine biosynthetic genes and the other genes of the regulon

\begin{tabular}{|c|c|c|}
\hline Gene & Enzyme name & EC no. \\
\hline $\arg A$ & NAGSase & 2.3.1.1 \\
\hline $\arg B^{*}$ & $\mathrm{~N}$-Acetylglutamate 5-phosphotransferase & 2.7.2.8 \\
\hline $\arg C^{*}$ & $\mathrm{~N}$-Acetylglutamate 5-phosphate reductase & 1.2.1.38 \\
\hline $\arg D$ & $\mathrm{~N}$-Acetylornithine 5 -aminotransferase & 2.6.1.11 \\
\hline $\arg E^{*}$ & $N$-Acetylornithinase & 3.5.1.16 \\
\hline $\operatorname{argF}$ & OTCase & 2.1.3.3 \\
\hline $\arg I$ & OTCase & 2.1.3.3 \\
\hline $\arg G$ & Argininosuccinate synthetase & 6.3 .4 .5 \\
\hline $\arg H^{*}$ & Argininosuccinate lyase & 4.3.2.1 \\
\hline $\operatorname{carA}^{*}$ & CPSase, subunit A & 6.3 .5 .5 \\
\hline $\operatorname{carB}^{*}$ & CPSase, subunit B & 6.3.5.5 \\
\hline $\operatorname{art} P \dagger$ & Subunit of the arginine $A B C$ transporter & \\
\hline $\operatorname{artI} \dagger$ & Subunit of the arginine $\mathrm{ABC}$ transporter & \\
\hline $\operatorname{art} Q^{\dagger}$ & Subunit of the arginine $\mathrm{ABC}$ transporter & \\
\hline $\operatorname{art} M \dagger$ & Subunit of the arginine $\mathrm{ABC}$ transporter & \\
\hline art $\dagger \dagger$ & Subunit of the arginine $\mathrm{ABC}$ transporter & \\
\hline hisJ丰 & Subunit of the histidine $A B C$ transporter & \\
\hline his $Q \ddagger$ & $\begin{array}{l}\text { Subunit of the lysine/arginine/ornithine } \mathrm{ABC} \\
\text { transporter and of histidine } \mathrm{ABC} \text { transporter }\end{array}$ & \\
\hline hisM $\ddagger$ & $\begin{array}{l}\text { Subunit of the lysine/arginine/ornithine } \mathrm{ABC} \\
\text { transporter and of histidine } \mathrm{ABC} \text { transporter }\end{array}$ & \\
\hline his $P \ddagger$ & $\begin{array}{l}\text { Subunit of the lysine/arginine/ornithine } \mathrm{ABC} \\
\text { transporter and of histidine } \mathrm{ABC} \text { transporter }\end{array}$ & \\
\hline
\end{tabular}

${ }^{*} \operatorname{argECBH}$ and $\operatorname{car} A B$ are organized in operons.

$\dagger$ Member of the regulon confirmed in this study.

$\ddagger$ Member of the regulon identified in this study. 
Table 3. Repression and derepression/repression ratios measured by hybridization to microarrays

min, Minimal medium; arg, minimal medium supplemented with arginine.

\begin{tabular}{|c|c|c|c|c|c|c|}
\hline \multirow[t]{2}{*}{ Gene } & \multicolumn{3}{|c|}{$\mathrm{P} 4 \mathrm{X}(\min ) / \mathrm{P} 4 \mathrm{X}(\arg )$ repression } & \multicolumn{3}{|c|}{$\mathrm{P} 4 \mathrm{XB} 2(\arg ) / \mathrm{P} 4 \mathrm{X}(\arg )$ derepression/repression } \\
\hline & $\log _{2}$ & Ratio & $P$ value & $\log _{2}$ & Ratio & $P$ value \\
\hline $\arg B$ & $2 \cdot 58$ & $6 \cdot 0$ & $1 \cdot 31 \times 10^{-3}$ & $3 \cdot 94$ & $15 \cdot 3$ & $4 \cdot 88 \times 10^{-6}$ \\
\hline $\arg C$ & $2 \cdot 77$ & $6 \cdot 8$ & $1.92 \times 10^{-4}$ & $3 \cdot 81$ & $14 \cdot 0$ & $1 \cdot 71 \times 10^{-6}$ \\
\hline $\arg D$ & $2 \cdot 33$ & $5 \cdot 0$ & $1 \cdot 78 \times 10^{-5}$ & $3 \cdot 28$ & $9 \cdot 7$ & $1 \cdot 37 \times 10^{-7}$ \\
\hline $\arg F$ & $2 \cdot 98$ & $7 \cdot 9$ & $1 \cdot 91 \times 10^{-4}$ & $4 \cdot 62$ & $24 \cdot 6$ & $6 \cdot 25 \times 10^{-7}$ \\
\hline $\arg I$ & $1 \cdot 36$ & $2 \cdot 6$ & $4 \cdot 37 \times 10^{-2}$ & $3 \cdot 44$ & $10 \cdot 9$ & $3 \cdot 36 \times 10^{-6}$ \\
\hline $\arg G$ & $2 \cdot 56$ & $5 \cdot 9$ & $1 \cdot 78 \times 10^{-5}$ & $3 \cdot 38$ & $10 \cdot 4$ & $1.62 \times 10^{-7}$ \\
\hline $\operatorname{argH}$ & $1 \cdot 67$ & $3 \cdot 2$ & $1.48 \times 10^{-2}$ & $3 \cdot 36$ & $10 \cdot 3$ & $8 \cdot 15 \times 10^{-6}$ \\
\hline carA & & & & $1 \cdot 71$ & $3 \cdot 3$ & $1 \cdot 11 \times 10^{-3}$ \\
\hline carB & & & & $1 \cdot 10$ & $2 \cdot 1$ & $3.06 \times 10^{-2}$ \\
\hline $\operatorname{artM}$ & $1 \cdot 25$ & $2 \cdot 4$ & $6.79 \times 10^{-4}$ & $1 \cdot 54$ & $2 \cdot 9$ & $1.77 \times 10^{-5}$ \\
\hline artJ & $3 \cdot 56$ & $11 \cdot 8$ & $3.47 \times 10^{-6}$ & $5 \cdot 07$ & $33 \cdot 6$ & $1 \cdot 34 \times 10^{-8}$ \\
\hline hisJ & $1 \cdot 31$ & $2 \cdot 5$ & $2 \cdot 10 \times 10^{-2}$ & $1 \cdot 91$ & $3 \cdot 8$ & $1.97 \times 10^{-4}$ \\
\hline hisQ & $1 \cdot 26$ & $2 \cdot 4$ & $7 \cdot 47 \times 10^{-3}$ & $1 \cdot 19$ & $2 \cdot 3$ & $1.72 \times 10^{-3}$ \\
\hline hisM & $1 \cdot 35$ & $2 \cdot 6$ & $1.29 \times 10^{-2}$ & $1 \cdot 21$ & $2 \cdot 3$ & $3 \cdot 81 \times 10^{-3}$ \\
\hline his $P^{*}$ & $0 \cdot 90$ & $1 \cdot 9$ & $1 \cdot 48 \times 10^{-2}$ & $0 \cdot 56$ & $1 \cdot 5$ & $3 \cdot 27 \times 10^{-2}$ \\
\hline
\end{tabular}

${ }^{\star}$ The ratio for hisP, even if below significance, is reported to complete the hisJQMP operon results.

The results for the $\operatorname{argECBH}$ operon reflect its transcriptional organization quite well: $\operatorname{argCBH}$ and $\operatorname{argE}$ are transcribed divergently from a control region containing a common operator site. Both $\operatorname{argE}$ and $\operatorname{argH}$ are also transcribed from weak secondary promoters which escape repression. This is shown by a lower derepression/repression ratio for $\arg E(4 \cdot 3)$ than for $\operatorname{argCBH}$, and by a lower ratio for $\operatorname{argH}(10 \cdot 3)$ than for $\operatorname{argC}(14 \cdot 0)$ and $\operatorname{argB}(15 \cdot 3)$.

The $\mathrm{P} 4 \mathrm{X}(\mathrm{min})$ to $\mathrm{P} 4 \mathrm{X}(\arg )$ ratio for the $\operatorname{car} A B$ operon was below the cut-off value as expected from the only partial (40\%) repression of $c a r A B$ by arginine (Piette et al., 1984). Indeed, liganded ArgR efficiently represses initiation at the downstream promoter carP2, but has no effect on transcription initiated at the upstream promoter carP1, which is mainly repressed by excess pyrimidines. Similarly, the weak autorepression of $\arg R$, the repressor gene, was below the detection level.

Only a few genes outside those of arginine biosynthesis were identified by the microarray analysis: the art genes encoding the arginine-specific uptake system and the hisJQMP genes of the histidine transporter complex (see below). Each one of these genes or gene clusters is preceded by one ARG box, the ArgR-binding component of arginine operators. It should be pointed out that a screening of the genomic sequence for ARG boxes (Makarova et al., 2001) identified only 11 operators or putative operator sites: those of the biosynthetic genes, of $\operatorname{argR}$ and of $\operatorname{artPIQM}$ and artJ, but failed to detect the box upstream of the hisJQMP cluster as well as the 6 or 7 putative boxes in the promoter region of the arginine catabolism ast operon (Lu, 2006). Since ARG boxes are partially conserved, the results of such a screening depend very much on the stringency of the search. Clearly, transcriptome analysis with DNA microarrays is a more sensitive approach, even with the high cut-off value applied in this study. Besides, the presence of an ARG box cannot by itself establish that a gene is part of the regulon without supporting evidence of ArgR-dependent regulation.

Analysis of the transcriptional repression of biosynthetic genes by the more sensitive RTq-PCR assay gave higher derepression/repression ratios than the microarrays (Table 4), closer to values obtained from enzyme specific activities (last column of Table 4 and below). The derepression/repression ratios range from 3 and 1.6 for car $A B$ to 150 for $\operatorname{argF}$, illustrating the flexibility conferred to the system by the regulon type of organization. When these ratios are put in context with the position of the genes and the cognate enzymic reactions in the pathway, a rough regulatory logic emerges. The pathway can be divided into three modules (Fig. 1): (i) the synthesis of ornithine from glutamate $(\arg A-\arg E)$, (ii) the synthesis of CP $(\operatorname{car} A B)$, and (iii) the synthesis of arginine from ornithine and CP $(\operatorname{argF} /$ 
Table 4. Relative genes expression measured with RTq-PCR, and derepression/repression ratios based on enzymic activity

The expression of P4X on unsupplemented minimal medium ( $\mathrm{min}$ ) was chosen as the reference value of $100 \%$. The effect of arginine addition (arg) was measured after 2 min, when full repression was achieved.

\begin{tabular}{|c|c|c|c|c|c|c|}
\hline Gene & P4X (min) & P4X (arg) & $\mathrm{P} 4 \mathrm{XB} 2$ (min) & P4XB2（arg) & $\begin{array}{c}\text { P4XB2 }(\arg ) / \mathrm{P} 4 \mathrm{X}(\arg ) \\
\text { Derepression/repression ratios* }\end{array}$ & $\begin{array}{c}\text { Derepression/repression ratio } \\
\text { based on enzyme activity }\end{array}$ \\
\hline $\arg A$ & $100 \pm 6$ & $13 \pm 1$ & $530 \pm 130$ & $560 \pm 120$ & $43 \cdot 1(37 \cdot 0)$ & $9 \dagger$ \\
\hline $\arg C$ & $100 \pm 18$ & $8 \pm 1$ & $690 \pm 80$ & $590 \pm 30$ & $73 \cdot 8(85 \cdot 0)$ & $60 \ddagger$ \\
\hline $\arg D$ & $100 \pm 10$ & $14 \pm 1$ & $350 \pm 60$ & $380 \pm 60$ & $27 \cdot 1$ & $16 \ddagger$ \\
\hline $\arg E$ & $100 \pm 1$ & $25 \pm 6$ & $180 \pm 10$ & $190 \pm 20$ & $7 \cdot 6(10 \cdot 0)$ & $17 \S$ \\
\hline $\arg F$ & $100 \pm 10$ & $15 \pm 3$ & $2190 \pm 210$ & $2270 \pm 110$ & $151 \cdot 3$ & $475 \dagger 11$ \\
\hline $\operatorname{argI}$ & $100 \pm 4$ & $11 \pm 3$ & $340 \pm 25$ & $300 \pm 30$ & $27 \cdot 3$ & $350 \ddagger$ \\
\hline $\arg G$ & $100 \pm 9$ & $21 \pm 1$ & $725 \pm 100$ & $630 \pm 70$ & $30 \cdot 0$ & \\
\hline carA & $100 \pm 1$ & $45 \pm 10$ & $160 \pm 20$ & $140 \pm 20$ & $3 \cdot 1$ & $2 \dagger$ \\
\hline $\operatorname{carB}$ & $100 \pm 7$ & $64 \pm 3$ & $130 \pm 10$ & $100 \pm 1$ & $1 \cdot 6$ & \\
\hline $\arg R$ & $100 \pm 7$ & $22 \pm 5$ & & & NA & \\
\hline $\operatorname{art} P$ & $100 \pm 3$ & $23 \pm 1$ & $130 \pm 20$ & $130 \pm 20$ & $5 \cdot 7$ & \\
\hline artJ & $100 \pm 9$ & $7 \pm 1$ & $325 \pm 40$ & $360 \pm 40$ & $51 \cdot 4(47 \cdot 5)$ & \\
\hline hisJ & $100 \pm 7$ & $35 \pm 8$ & $125 \pm 1$ & $105 \pm 10$ & $3 \cdot 0(2 \cdot 8)$ & \\
\hline $\arg P$ & $100 \pm 10$ & $82 \pm 10$ & $93 \pm 10$ & $83 \pm 10$ & $1 \cdot 0$ & \\
\hline $\arg T$ & $100 \pm 13$ & $81 \pm 13$ & $110 \pm 20$ & $94 \pm 20$ & $1 \cdot 2$ & \\
\hline
\end{tabular}

${ }^{*}$ Values between parentheses are ratios obtained from RNAprotect-treated samples. NA, Not applicable.

$†$ This study.

¥From Charlier \& Glansdorff (2004).

$\S$ From Cunin et al. (1983).

IIOTCase activities are the sum of $\arg F$ and $\operatorname{argI}$ expressions.

$I-\operatorname{argH})$. (i) A substantial repression of $\operatorname{argA}$ (43-fold) and feedback inhibition of NAGSase by arginine (Marvil \& Leisinger, 1977; Caldara et al., 2005) combine to control the metabolic flow through the first part of the pathway and thus the production of ornithine. (ii) Repression of carAB by arginine is only partial (about threefold) but the activity of CPSase is subject to a complex set of allosteric regulations, among which are a strong feedback inhibition by UMP and a counteracting activation by ornithine (Piérard et al., 1965; Robin et al., 1989; Braxton et al., 1992). Limitation of ornithine production by arginine therefore enhances the feedback inhibition of CPSase by UMP. (iii) The strong repression of $\operatorname{argF}$ (150-fold) and $\operatorname{argI}$ (27-fold) makes OTCase synthesis the most repressible step of the pathway (475-fold repression of total OTCase activity; Table 4) and the major control point of the metabolic flux from ornithine to arginine. Arginine itself does not directly regulate the activity of OTCase, but it limits the availability of $\mathrm{CP}$, the second substrate of the enzyme, which amounts to an inhibition of this enzymic step, and enhances its control of the metabolic flux to arginine.

The $\arg F$ and $\operatorname{argI}$ transcriptional regulation profiles, $\arg F$ being more repressible (150-fold) than $\operatorname{argI}$ (27-fold), differ from ratios obtained previously from enzyme assays in strains containing one or other of these genes, which show a greater derepression/repression ratio for argI. This could be explained by different translation efficiencies for these genes or by the use of non-strictly isogenic conditions in the original enzyme assays (Charlier \& Glansdorff, 2004).

Amplitudes of transcriptional repression parallel those calculated from enzyme specific activities, but they are smaller, with the exception of $c a r A B$, as observed previously (Cunin et al., 1986), $\arg A$ and $\operatorname{argC}$ (Table 4). The discrepancy between transcriptional and enzymic repression amplitudes led us to consider for a while the existence of a post-transcriptional control, e.g. attenuation. However, systematic investigations of the transcription of the $\operatorname{argECBH}$ operon and the sequences of the biosynthetic genes control regions did not support the existence of such a control (Beny et al., 1982; Charlier et al., 1992). The better correspondence obtained when transcription is measured by RTq-PCR indicates that, next to fine adjustments in response to global or cross-pathway signals, one cause of the discrepancy between ratios is probably methodological rather than related to post-transcriptional regulation.

The autorepression of $\operatorname{argR}$ was detected by RTq-PCR, with a ratio of 5 between the wild-type on minimal medium and on arginine-supplemented medium (Table 4).

No arginine catabolic gene was found to respond to arginine in the microarray experiments, which is not surprising since these genes respond to nitrogen limitation (Reitzer, 1996), a condition not examined here since all media contained ammonia. Only when arginine is the sole nitrogen 


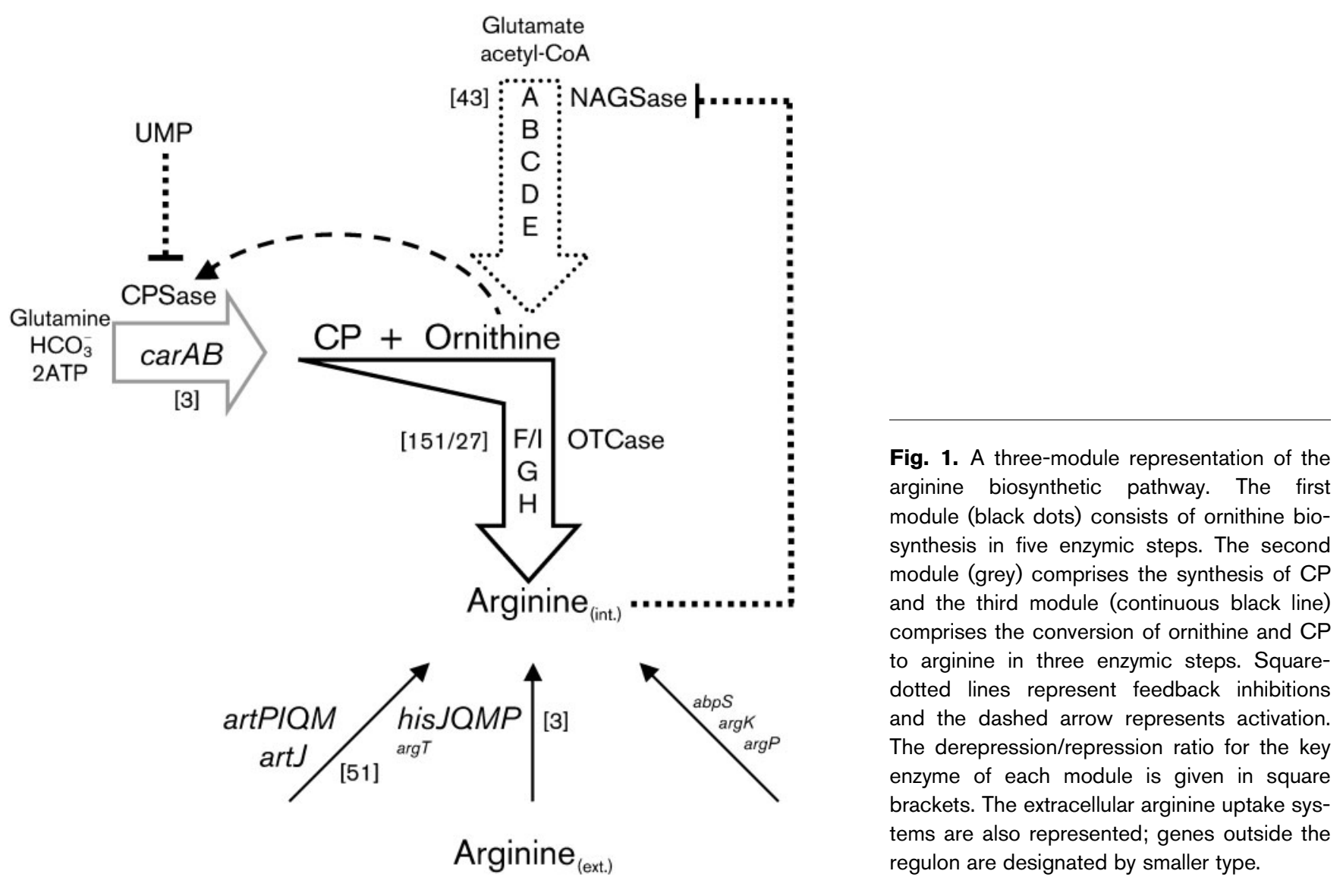

source - again not the case here - is there an ArgRdependent component to the induction of the arginine succinyltransferase (AST) pathway (a two- to threefold effect) (Kiupakis \& Reitzer, 2002).

Arginine uptake genes. Three arginine uptake systems have been identified in E. coli, which use distinctive periplasmic binding proteins: (i) the arginine-specific system encoded by the artPIQM and artJ genes (Wissenbach et al., 1995); (ii) the basic amino acid uptake system, designated LAO (lysine, arginine, ornithine) (Rosen, 1971; Celis et al., 1973); and (iii) the less well characterized AO system transporting arginine and ornithine (Celis, 1977a).

(i) The arginine-specific system. This system is encoded by the artPIQM and artJ genes (Wissenbach et al., 1993) (Fig. 2). ArtJ is an arginine-binding protein, and ArtP, ArtQ and ArtM are similar to the membraneous and membrane-associated components of binding-proteindependent carrier systems (Wissenbach et al., 1995). The artPIQM and artJ transcription units of the arginine-specific system are differentially repressed by arginine, with derepression/repression coefficients of 6 for $\operatorname{art} P$, the first gene of the artPIQM operon, and 53 for artJ (Table 4). Both artPIQM and artJ are preceded by a single ARG box (Makarova et al., 2001) and repression is indeed mediated by $\operatorname{ArgR}$, as shown by the increased mRNA levels in
P4XB2 (Tables 3 and 4). This establishes unambiguously that the genes of this uptake system are organized in at least two distinct transcription units which are integral components of the arginine regulon. The repression control of artJ is strong (53-fold), an apparent regulatory logic behind this being that intracellular arginine controls the uptake of extracellular arginine by strongly repressing the first component of the system, the periplasmic binding protein. This is consistent with this system being the major arginine uptake system of $E$. coli under aerobic growth conditions and in the presence of sufficient nitrogen.

(ii) The basic amino acid LAO system. The LAO system consists of the $\operatorname{argT}$-encoded periplasmic LAO protein which binds lysine, arginine and ornithine, and membraneous and membrane-associated proteins encoded by the hisJQMP genes which encode the histidine transporter, a complex that has not been studied extensively in E. coli but has been well studied in Salmonella enterica serovar Typhimurium (Ames, 1986; Liu \& Ames, 1998). HisJ is a periplasmic histidine-binding protein. HisP is involved in histidine as well as arginine transport (Kustu \& Ames, 1973; Kustu et al., 1979). In E. coli, the genes are organized in two adjacent transcription units of identical polarity, $\operatorname{argT}$ and hisJQMP (Fig. 2), whose expression is positively controlled by the nitrogen regulatory protein $\mathrm{NtrC}$ in response to nitrogen starvation (Zimmer et al., 
(a)

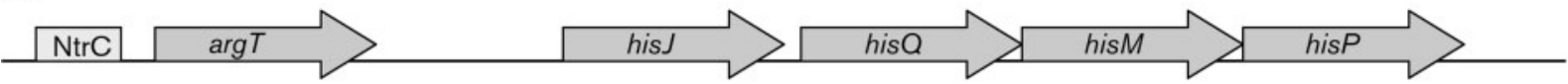

(b)

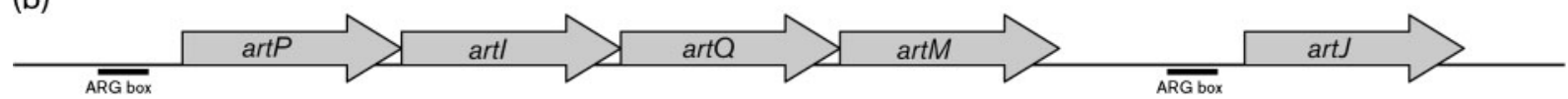

Fig. 2. Diagram of LAO basic amino acid transporter genes (a) and arginine-specific transport genes (b) with the relative position of the two ARG boxes indentified by Makarova et al. (2001) indicated.

2000). The NtrC regulatory site is located upstream of $\arg$. The present analysis reveals that the hisJQMP genes are subject to ArgR-mediated repression (Table 3) with a derepression/repression coefficient of 3-4 for hisJ (Tables 3 and 4). RTq-PCR analysis shows that $\arg T$ is not repressed by arginine and that its transcription remains unchanged in the $\operatorname{argR}$ mutant (Table 3). Therefore, the repression of hisJQMP by arginine is specific to this operon, which makes it a member of the regulon. A putative ARG box was identified between $\arg T$ and hisJQMP, upstream of the promoter, and its involvement in repression was investigated (see next section).

The histidine transporter appears to be the only histidine uptake system in E. coli. This could explain its comparatively weak response to arginine, leaving sufficient residual expression to ensure the uptake of histidine. Arginine transport by the LAO system appears to be essentially confined to the scavenging of a nitrogen-rich amino acid under conditions of nitrogen starvation.

(iii) The AO system. This consists of the $a b p S$ and $\operatorname{argK}$ genes, AbpS ( $\mathrm{AO})$ being a binding protein and ArgK an ATP hydrolase whose activity is required for transport (Celis et al., 1998). The regulation of $a b p S$ and $\operatorname{argK}$ is ArgR-independent (Celis, 1977b), yet uptake by this system is repressed by arginine (Celis et al., 1973). Since the exact location of $a b p S$ is still not known and the level of $\operatorname{argK}$ expression is very low, making it difficult to quantify it correctly, we focussed on $\arg P$, the transcription activator of the system. The contention that $\operatorname{ArgP}$ represses its own synthesis in the presence of arginine (Celis, 1999) is not supported by our data (Table 4), concurring with more recent evidence obtained with $\operatorname{argP}$ lacZ fusions (Nandineni \& Gowrishankar, 2004). It was shown previously that single mutants affected arginine uptake by both the $\mathrm{AO}$ and the LAO systems, suggesting that these systems share one or more elements downstream of the periplasmic binding step (Celis et al., 1973; Rosen, 1973). In S. enterica serovar Typhimurium, HisP participates in both histidine and arginine transport (Kustu \& Ames, 1973; Kustu et al., 1979). The similarity of the Salmonella and E. coli histidine transporters (Liu \& Ames, 1998) suggests a similar dual involvement of HisP in E. coli. In that case, arginine could control the uptake of histidine by the AO system through the repression of hisJQMP.

\section{Arginine repression of the histidine transporter genes}

The functionality of the putative ARG box AATGAAAAATAATACGTC located 120-103 bp upstream of the hisJ start codon was tested by measuring arginine repression in a set of reporter fusions with lac $Z$, and by electrophoretic mobility shift experiments in the presence of pure ArgR repressor.

Repression assays. In vivo repression of the hisJ promoter was assayed with single-copy $\mathrm{F}^{\prime}$-borne hisJ-lacZ reporter fusion constructs. The derepression/repression ratio for $\beta$-galactosidase $(3 \cdot 8$-fold, in good agreement with the transcriptome data, $3 \cdot 8$ and 3.0 ) was observed only when the whole $220 \mathrm{bp}$ region between $\arg T$ and hisJQMP, containing the hisJQMP promoter, was inserted (WT $\mathrm{p}_{\text {hisJQMP }}$; Fig. 3). This repression was abolished in a strain containing a deletion of the $\operatorname{argR}$ gene (FW102 $\Delta \operatorname{argR}$ ). Disrupting the ARG box by the insertion of an FRT sequence (ARG box-KO), deleting the region upstream of the ARG box $\left(\Delta 1 \mathrm{p}_{\text {hisJQMP }}\right)$, or the same region plus the ARG box $\left(\Delta 2 p_{\text {hisJQMP }}\right)$ abolished repression (Fig. 3). This indicates that in addition to the ARG box, part of the $100 \mathrm{bp}$ upstream region is also required for repression, although, based on in silico analysis, it does not contain any sequence remotely similar to an ARG box.

Gel mobility shift assays. Mobility shift assays with purified ArgR binding to the wild-type control region of the hisJQMP operon in the presence of a large excess of nonspecific competitor DNA showed the formation of a single retarded complex, indicating that ArgR binds specifically to this fragment with an apparent equilibrium dissociation constant around $8 \mu \mathrm{M}$ (Fig. $4 \mathrm{a}$ ). In contrast, binding to the equivalent fragment bearing the ARG box$\mathrm{KO}$ region required higher protein concentrations and resulted in the formation of unstable and non-specific complexes as indicated by the intense smearing and the ArgR concentration-dependent position of the retarded DNA (Fig. 4b). These results show that the ARG box is a major recognition element for $\operatorname{ArgR}$ in the hisJQMP operator and suggest that part of the $100 \mathrm{bp}$ region 


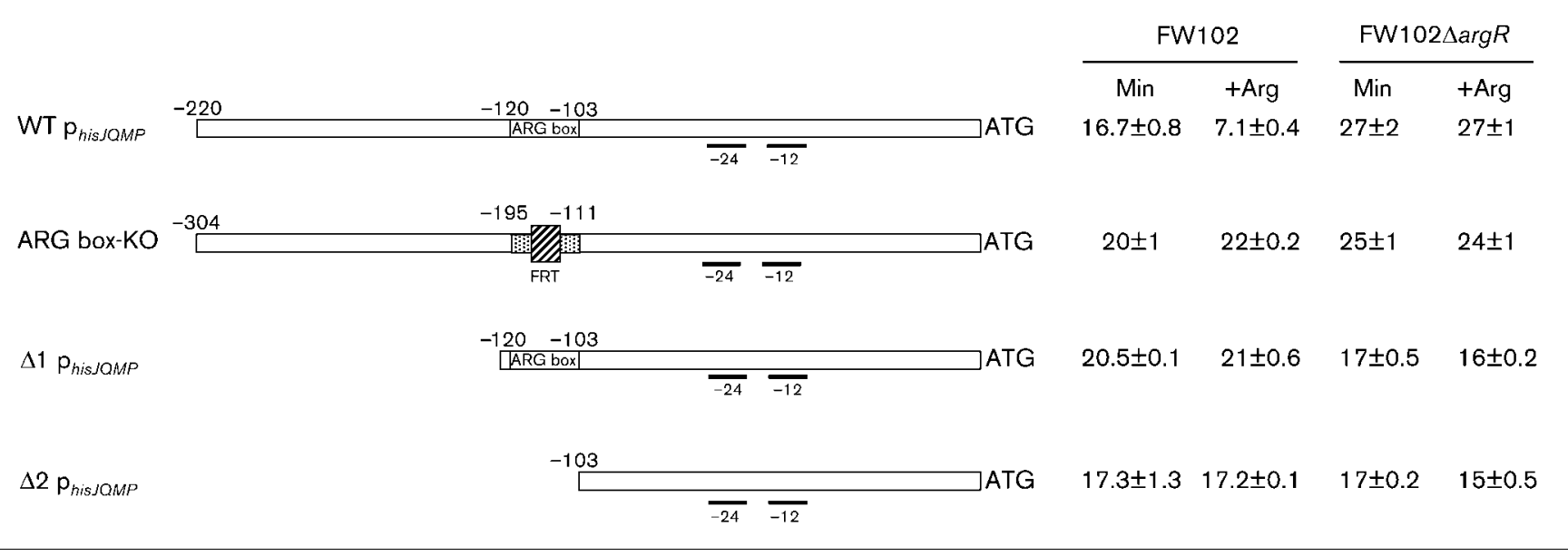

Fig. 3. Promoter constructs used to characterize the functionality of the identified ARG box and the relative $\beta$-galactosidase activity. The position of the conserved promoter sequences $(-12 /-24)$ is indicated. The nucleotide positions are reported with respect to the ATG starting codon. $\beta$-Galactosidase activity was assayed in FW102 or in its genetically derepressed derivative FW102 $\triangle \mathrm{arg} R$ and in the absence or presence of arginine as indicated, and is expressed as $\mu \mathrm{mol} \mathrm{h}^{-1}$ (mg protein) ${ }^{-1}$.

upstream of the box may also interact with the repressor. Taken together with the repression assays, these results strongly suggest that full arginine-dependent repression of hisJQMP requires binding of a repressor not only to the ARG box, but also to as-yet-unidentified upstream sequences to strengthen and stabilize the interaction. Further analysis of ArgR interaction with DNA (e.g. by using footprinting) is needed to elucidate the role of the upstream region.

\section{Dynamics of the regulon: time course of repression}

The time course of repression was monitored using RTqPCR and parallel assays of selected enzymic activities. The

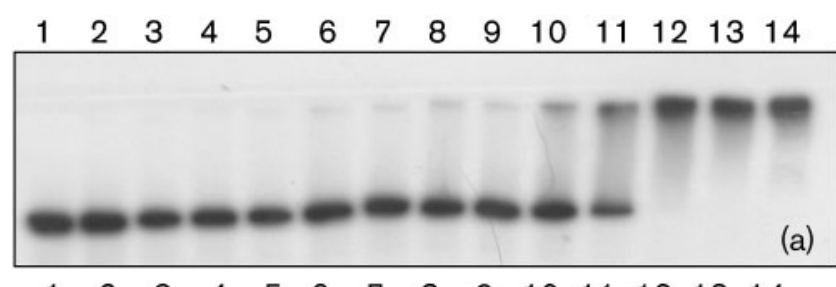

$\begin{array}{llllllllllllll}1 & 2 & 3 & 4 & 5 & 6 & 7 & 8 & 9 & 10 & 11 & 12 & 13 & 14\end{array}$

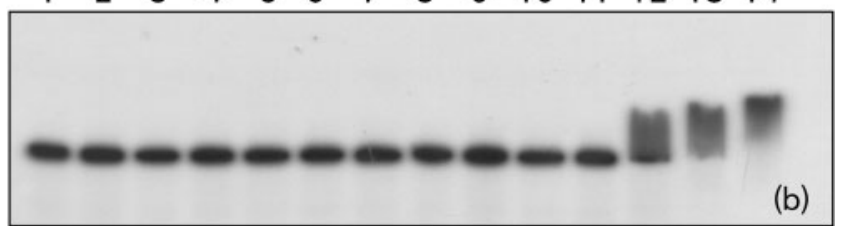

Fig. 4. Gel mobility shift assay. The wild-type promoter region of the WT $\mathrm{p}_{\text {hisJOMP }}$ operon (a) or the mutant ARG box KO (b) was PCR-amplified and labelled. Approximately $10 \mathrm{pM}$ DNA was loaded. Lane 1 contains no protein; lanes 2-14 contain $0 \cdot 4,0 \cdot 8,1 \cdot 2,1 \cdot 6,2,2 \cdot 4,2 \cdot 8,4,6,8,16,24$ and $40 \mu \mathrm{M}$ pure ArgR repressor. evolution of mRNA and enzyme levels after arginine addition is shown in Figs 5 and 6. Initial experiments with measurements every minute over a 15 min range (data not shown) showed that transcriptional repression was already complete 2 min after arginine addition. Therefore, the time course was followed with measurements every $30 \mathrm{~s}$ over a 2 min range (Fig. 5). In contrast, it took 45-60 min for the NAGSase and OTCase activities to reach $50 \%$ of their initial level, and $90 \mathrm{~min}$ for CPSase activity to reach its full repression level (Fig. 6). A $60 \mathrm{~min}$ period of time corresponds to one generation time of the chemostat culture. Taken together, these results show that while the ArgR-mediated response at the gene level is very fast, the enzymes are rather stable, their activities being either diluted pro rata of the cells doubling time in the case of NAGSase and OTCase, or possibly following a slightly different course in the case of CPSase. Whatever the molecular mechanism(s) involved in these different cases, the fact remains that a considerable residual enzymic activity is still present after the addition of arginine. Thus feedback inhibition by arginine of the first biosynthetic enzyme, NAGSase, must play a major role in controlling the metabolic flux in the first module of the biosynthesis immediately after the onset of repression with an impact, through reduced ornithine production, on CPSase activity (second module) (less antagonizing of UMP inhibition by ornithine) and, in turn, through limitation of $\mathrm{CP}$ production, on the conversion of ornithine to arginine (third module).

\section{Conclusions}

Transcriptome analysis showed that the major component of genetic repression in the arginine regulon is transcriptional and ArgR-mediated. The use of the sensitive RTqPCR method to assay mRNAs yielded derepression/ repression transcription ratios much closer to those calculated from specific enzymic activities than the ratios 


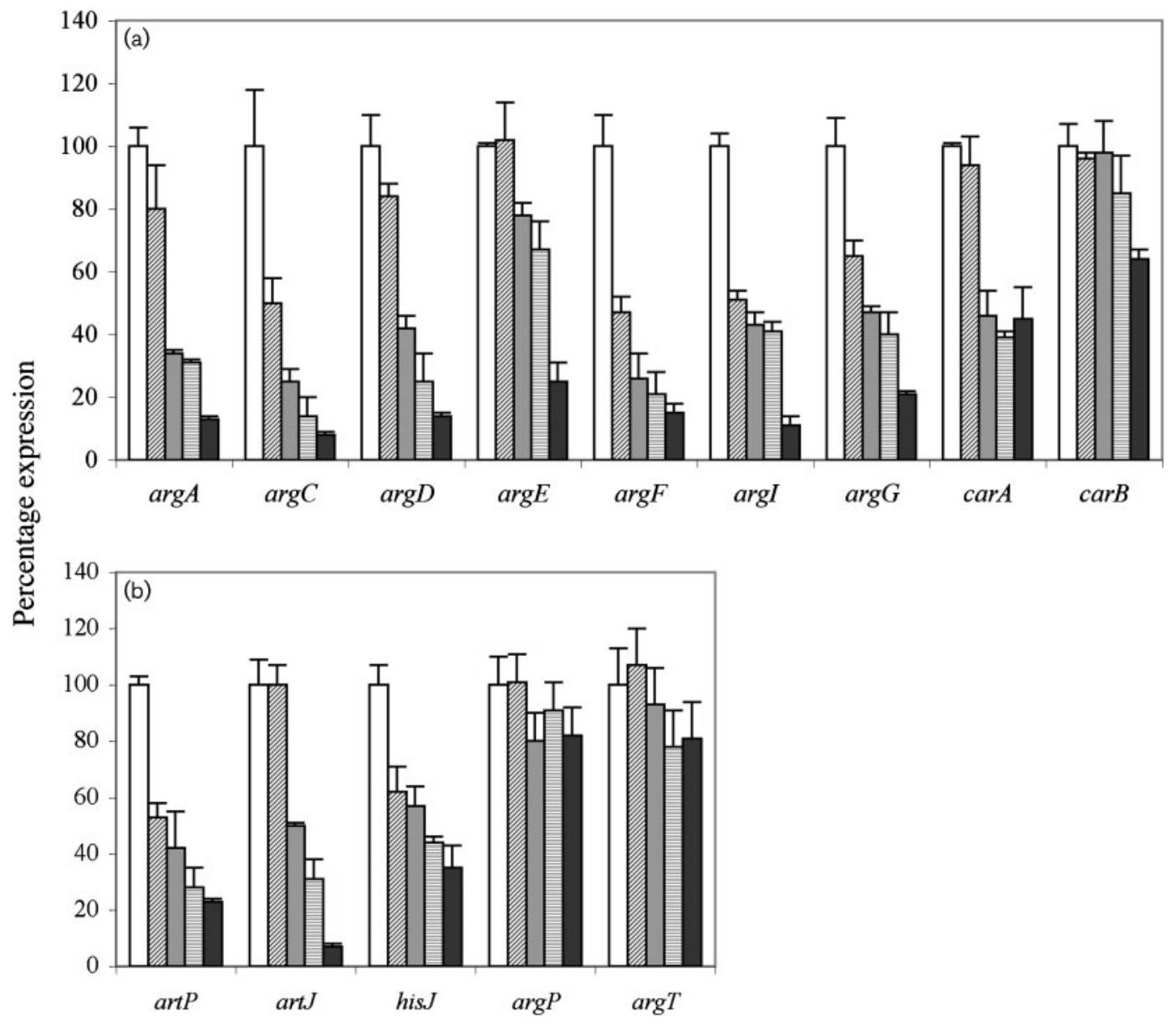

Fig. 5. Relative expression levels of the genes of arginine biosynthesis (a) and transport and transport-related genes (b) after addition of L-arginine to the medium. Samples were collected at intervals of $30 \mathrm{~s}$ until 2 min after addition of L-arginine. All the values are relative to the expression measured in the wild-type ( $\mathrm{P} 4 \mathrm{X})$ on unsupplemented minimal medium (time zero). White bars, $0 \mathrm{~s}$; diagonal-hatched bars, $30 \mathrm{~s}$; grey bars, $60 \mathrm{~s}$; horizontal-hatched bars, $90 \mathrm{~s}$; black bars, $120 \mathrm{~s}$.

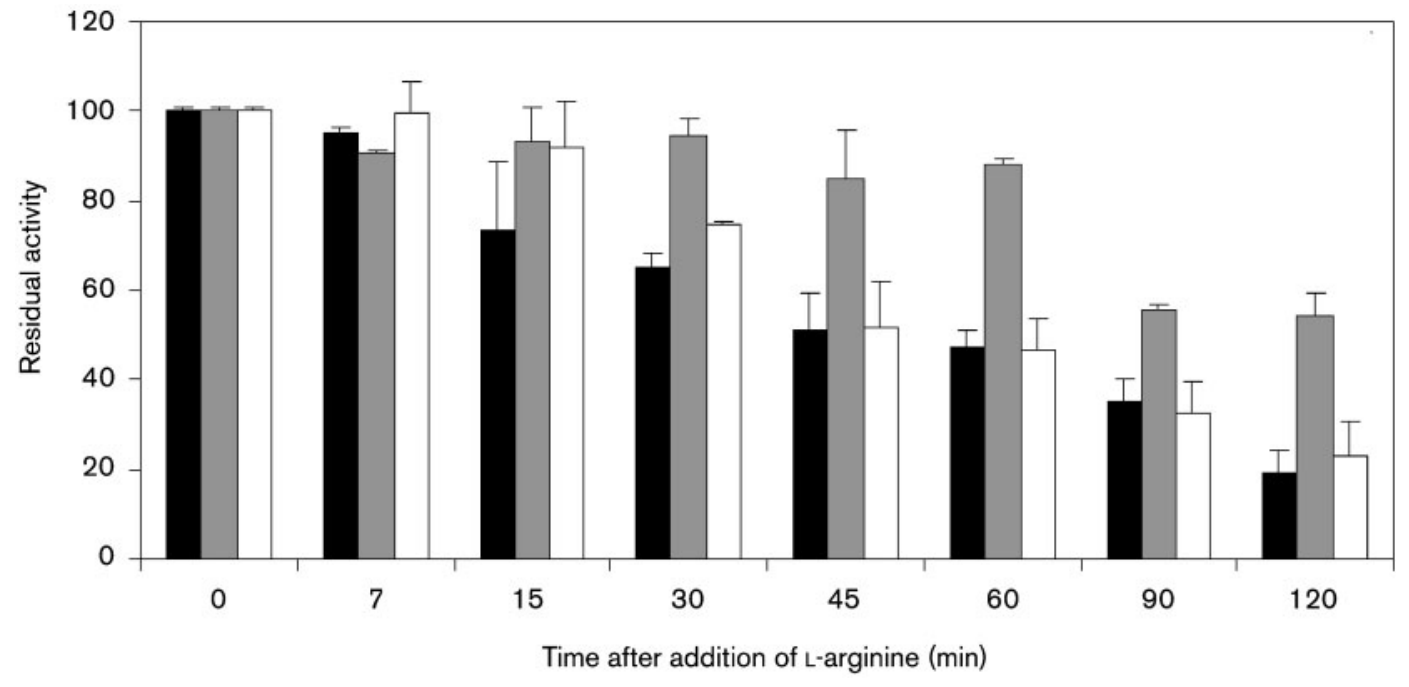

Fig. 6. Residual activity of key enzymes NAGSase (dark grey bars), CPSase (light grey bars) and OTCase (white bars) after the addition of L-arginine. 
previously obtained by filter or liquid RNA-DNA hybridization, thus showing that eventual additional transcriptional or post-transcriptional regulations are limited in amplitude and must correspond to fine adjustments of the system in response to global or cross-pathway signals. The enhancement of the synthesis of the enzymes encoded by $\arg A, \arg E, \operatorname{argI}$ and $\operatorname{argH}$ by ppGpp, the chemical messenger of the stringent response (Gallant, 1979; Kelker \& Eckhardt, 1977; Zidwick et al., 1984) and the effect of cAMP/ CAP on $\arg G$ (Krin et al., 2003) fall into this category of controls.

Hybridization to microarrays identified the histidinetransporter-encoding hisJQMP operon as a new member of the arginine regulon, subject to weak ArgR-mediated repression by arginine. The corresponding gene products are part of the LAO basic amino acids uptake system, part of a scavenging defence against nitrogen limitation (Zimmer et al., 2000). In contrast, the specific arginine uptake system (Wissenbach et al., 1993) is strongly repressed by arginine. The comparatively low response of the hisJQMP genes to arginine is probably related to the scavenging function of their products and also to the fact that this could be the only histidine uptake system operating in E. coli, and therefore a stronger arginine-dependent repression would be incompatible with histidine uptake. No evidence was found for ArgR-mediated regulation of the genes of the less well characterized AO uptake system (Celis et al., 1973). ArgRindependent regulation of the $\mathrm{AO}$ system by arginine has been proposed before (Celis, 1977a, b, 1999). Since the AO and LAO systems share at least one element downstream of the binding step (Celis et al., 1973), possibly HisP (Kustu et al., 1979), the present results suggest that the AO system could be regulated by arginine through the repression of the hisJQMP component of the LAO system. Altogether, this study clarifies the respective roles of the arginine uptake systems in E. coli.

The time course of repression experiments showed that maximal response of transcription to arginine is reached in 2 min, whereas the cognate enzymic activities decrease more slowly (pro rata of cell division in the case of NAGSase and OTCase). This emphasizes the importance of feedback inhibition of the first biosynthetic enzyme, NAGSase, in controlling the metabolic flux in biosynthesis immediately after the onset of repression.

\section{ACKNOWLEDGEMENTS}

This work was supported by grants G.0041.03 (to R. C.) and G.0421.06 (to D.C.) of the Fonds voor Wetenschappelijk Onderzoek Vlaanderen, and OZR837 of the Research Council of the Vrije Universiteit Brussel (VUB) to R. C. The authors are thankful to Drs P. Van Hummelen and S. Weckx of the Microarray Facility of the Flanders Interuniversity Institute for Biotechnology, to $\mathrm{Dr}$ L. Leyns, Laboratorium voor Cellulaire Genetica, VUB, for advice on RTqPCR and use of his facility, and to Dr M. Crabeel, VUB, for helpful discussions.

\section{REFERENCES}

Abadjieva, A., Pauwels, K., Hilven, P. \& Crabeel, M. (2001). A new yeast metabolon involving at least the two first enzymes of arginine biosynthesis: acetylglutamate synthase activity requires complex formation with acetylglutamate kinase. J Biol Chem 276, 42869-42880.

Ames, G. F. (1986). Bacterial periplasmic transport systems: structure, mechanism, and evolution. Annu Rev Biochem 55, 397-425.

Bachmann, B. J. (1987). Derivations and genotypes of some mutant derivatives of Escherichia coli K-12. In Escherichia coli and Salmonella: Cellular and Molecular Biology, 2nd edn, pp. 1190 - 1224. Edited by F. C. Neidhardt and others. Washington, DC: American Society for Microbiology.

Benjamini, Y. \& Hochberg, Y. (1995). Controlling the false discovery rate: a practical and powerful approach to multiple testing. $J R$ Stat Soc Ser B 57, 289-300.

Beny, G., Cunin, R., Glansdorff, N., Boyen, A., Charlier, J. \& Kelker, N. (1982). Transcription of regions within the divergent $\operatorname{argECBH}$ operon of Escherichia coli: evidence for lack of an attenuation mechanism. J Bacteriol 151, 58-61.

Braxton, B. L., Mullins, L. S., Raushel, F. M. \& Reinhart, G. D. (1992). Quantifying the allosteric properties of Escherichia coli carbamyl phosphate synthetase: determination of thermodynamic linkedfunction parameters in an ordered kinetic mechanism. Biochemistry 31, 2309-2316.

Caldara, M., Verbrugghe, K., De Vuyst, L., Crabeel, M., Dupont, G., Goldbeter, A. \& Cunin, R. (2005). Experimental manipulation and mathematical modelling of arginine biosynthesis in Escherichia coli. Abstract in Systems Biology: From Molecules \& Modelling to Cells (FEBS Course, Gosau, Austria), p. 145.

Celis, R. T. (1999). Repression and activation of arginine transport genes in Escherichia coli K-12 by the ArgP protein. J Mol Biol 294, 1087-1095.

Celis, R. T., Leadlay, P. F., Roy, I. \& Hansen, A. (1998). Phosphorylation of the periplasmic binding protein in two transport systems for arginine incorporation in Escherichia coli K-12 is unrelated to the function of the transport system. J Bacteriol 180, 4828-4833.

Celis, T. F. (1977a). Independent regulation of transport and biosynthesis of arginine in Escherichia coli K-12. J Bacteriol 130, 1244-1252.

Celis, T. F. (1977b). Properties of an Escherichia coli K-12 mutant defective in the transport of arginine and ornithine. J Bacteriol 130, 1234-1243.

Celis, T. F., Rosenfeld, H. J. \& Maas, W. K. (1973). Mutant of Escherichia coli $\mathrm{K}-12$ defective in the transport of basic amino acids. J Bacteriol 116, 619-626.

Charlier, D. (2004). Arginine regulation in Thermotoga neapolitana and Thermotoga maritima. Biochem Soc Trans 32, 310-313.

Charlier, D. \& Glansdorff, N. (2004). Biosynthesis of arginine and polyamines. In EcoSal (www.ecosal.org), Section 3.6.1.10. Edited by R. Curtiss III. Washington, DC: American Society for Microbiology.

Charlier, D., Roovers, M., Van Vliet, F., Boyen, A., Cunin, R., Nakamura, Y., Glansdorff, N. \& Pierard, A. (1992). Arginine regulon of Escherichia coli K-12. A study of repressor-operator interactions and of in vitro binding affinities versus in vivo repression. J Mol Biol 226, 367-386.

Cunin, R., Eckhardt, T., Piette, J., Boyen, A., Pierard, A. \& Glansdorff, N. (1983). Molecular basis for modulated regulation of gene expression in the arginine regulon of Escherichia coli K-12. Nucleic Acids Res 11, 5007-5019. 
Cunin, R., Glansdorff, N., Pierard, A. \& Stalon, V. (1986). Biosynthesis and metabolism of arginine in bacteria. Microbiol Rev 50, 314-352.

Datsenko, K. A. \& Wanner, B. L. (2000). One-step inactivation of chromosomal genes in Escherichia coli K-12 using PCR products. Proc Natl Acad Sci U S A 97, 6640-6645.

Devroede, N., Thia-Toong, T. L., Gigot, D., Maes, D. \& Charlier, D. (2004). Purine and pyrimidine-specific repression of the Escherichia coli car $A B$ operon are functionally and structurally coupled. $J \mathrm{Mol}$ Biol 336, 25-42.

Fried, M. G. \& Crothers, D. M. (1983). CAP and RNA polymerase interaction with lac promoter: binding stoichiometry and long range effects. Nucleic Acids Res 11, 141-158.

Gallant, J. A. (1979). Stringent control in E. coli. Annu Rev Genet 13, 393-415.

Gentleman, C. G., Carey, V. J., Bates, D. M., Bolstad, B., Dettling, M., Dudoit, S. \& 19 other authors (2004). Bioconductor: open software development for computational biology and bioinformatics. Genome Biol 5, R80.

Glansdorff, N. (1965). Topography of cotransducible arginine mutations in Escherichia coli K-12. Genetics 51, 167-179.

Glansdorff, N. \& Sand, G. (1965). Coordination of enzyme synthesis in the arginine pathway of Escherichia coli K-12. Biochim Biophys Acta 108, 308-311.

Irizarry, R. A., Hobbs, B., Collin, F., Beazer-Barclay, Y. D., Antonellis, K. J., Scherf, U. \& Speed, T. P. (2003). Exploration, normalization, and summaries of high density oligonucleotide array probe level data. Biostatistics 4, 249-264.

Jishage, M., Iwata, A., Ueda, S. \& Ishihama, A. (1996). Regulation of RNA polymerase sigma subunit synthesis in Escherichia coli: intracellular levels of four species of sigma under various growth conditions. J Bacteriol 178, 5447-5451.

Kelker, N. \& Eckhardt, T. (1977). Regulation of $\arg A$ operon expression in Escherichia coli K-12: cell-free synthesis of $\beta$ galactosidase under $\arg A$ control. J Bacteriol 132, 67-72.

Kiupakis, A. K. \& Reitzer, L. (2002). ArgR-independent induction and ArgR-dependent superinduction of the astCADBE operon in Escherichia coli. J Bacteriol 184, 2940-2950.

Krin, E., Laurent-Winter, C., Bertin, P. N., Danchin, A. \& Kolb, A. (2003). Transcription regulation coupling of the divergent $\arg G$ and metY promoters in Escherichia coli K-12. J Bacteriol 185, 3139-3146.

Kustu, S. G. \& Ames, G. F. (1973). The HisP protein, a known histidine transport component in Salmonella typhimurium, is also an arginine transport component. J Bacteriol 116, 107-113.

Kustu, S. G., McFarland, N. C., Hui, S. P., Esmon, B. \& Ames, G. F. (1979). Nitrogen control of Salmonella typhimurium: co-regulation of synthesis of glutamine synthetase and amino acid transport systems. J Bacteriol 138, 218-234.

Liu, P. Q. \& Ames, G. F. (1998). In vitro disassembly and reassembly of an ABC transporter, the histidine permease. Proc Natl Acad Sci U S A 95, 3495-3500.

Lu, C.-D. (2006). Pathways and regulation of bacterial arginine metabolism and perspectives for obtaining arginine overproducing strains. Appl Microbiol Biotechnol 70, 261-272.

Maas, W. K. \& Clark, A. J. (1964). Studies on the mechanism of repression or arginine biosynthesis in Escherichia coli. II. Dominance of repressibility in diploids. J Mol Biol 8, 365-370.
Makarova, K. S., Mironov, A. A. \& Gelfand, M. S. (2001) Conservation of the binding site for the arginine repressor in all bacterial lineages. Genome Biol 2, 1-8.

Marvil, D. K. \& Leisinger, T. (1977). N-Acetylglutamate synthase of Escherichia coli: purification, characterization, and molecular properties. J Biol Chem 252, 3295-3303.

Miller, H. J. (1972). Experiments in Molecular Genetics. Cold Spring Harbor, NY: Cold Spring Harbor Laboratory.

Nandineni, M. R. \& Gowrishankar, J. (2004). Evidence for an arginine exporter encoded by $\operatorname{yggA}(\operatorname{argO})$ that is regulated by the LysR-type transcriptional regulator ArgP in Escherichia coli. J Bacteriol 186, 3539-3546.

Piérard, A., Glansdorff, N., Mergeay, M. \& Wiame, J. M. (1965). Control of the biosynthesis of carbamoyl phosphate in Escherichia coli. J Mol Biol 14, 23-36.

Piette, J., Nyunoya, H., Lusty, C. J., Cunin, R., Weyens, G., Crabeel, M., Charlier, D., Glansdorff, N. \& Pierard, A. (1984). DNA sequence of the carA gene and the control region of car $A B$ : tandem promoters, respectively controlled by arginine and the pyrimidines, regulate the synthesis of carbamoyl-phosphate synthetase in Escherichia coli K-12. Proc Natl Acad Sci U S A 81, 4134-4138.

Reitzer, L. J. (1996). Sources of nitrogen and their utilization. In Escherichia coli and Salmonella: Cellular and Molecular Biology, 2nd edn, pp. 380-390. Edited by F. C. Neidhardt and others. Washington, DC: American Society for Microbiology.

Robin, J. P., Penverne, B. \& Hervé, G. (1989). Carbamoyl phosphate biosynthesis and partition in pyrimidine and arginine pathways of Escherichia coli. In situ properties of carbamoyl-phosphate synthase, ornithine transcarbamylase and aspartate transcarbamylase in permeabilized cells. Eur J Biochem 183, 519-528.

Rosen, B. P. (1971). Basic amino acid transport in Escherichia coli. J Biol Chem 246, 3653-3662.

Rosen, B. P. (1973). Basic amino acid transport in Escherichia coli: properties of canavanine-resistant mutants. J Bacteriol 116, 627-635.

Simmons, A. J., Rauwls, J. M., Piskur, J. \& Davidson, J. N. (1999). A mutation that uncouples allosteric regulation of carbamyl phosphate synthetase in Drosophila. J Mol Biol 287, 277-285.

Whipple, F. W. (1998). Genetic analysis of prokaryotic and eukaryotic DNA-binding proteins in Escherichia coli. Nucleic Acids Res 26, 3700-3706.

Wissenbach, U., Keck, B. \& Unden, G. (1993). Physical map location of the new artPIQMJ genes of Escherichia coli, encoding a periplasmic arginine transport system. J Bacteriol 175, 3687-3688.

Wissenbach, U., Six, S., Bongaerts, J., Ternes, D., Steinwachs, S. \& Unden, G. (1995). A third periplasmic transport system for L-arginine in Escherichia coli: molecular characterization of the artPIQMJ genes, arginine binding and transport. Mol Microbiol 17, 675-686.

Xu, Y., Sun, Y., Huysveld, N., Gigot, D., Glansdorff, N. \& Charlier, D. (2003). Regulation of arginine biosynthesis in the psychropiezophilic bacterium Moritella profunda: in vivo repressibility and in vitro repressor-operator contact probing. J Mol Biol 326, 353-369.

Zidwick, M. J., Korshus, J. \& Rogers, P. (1984). Positive control of expression of the $\operatorname{argECBH}$ gene cluster in vivo by $5^{\prime}$-diphosphate $3^{\prime}$ diphosphate. J Bacteriol 159, 647-651.

Zimmer, D. P., Soupene, E., Lee, H. L., Wendisch, V. F., Khodursky, A. B., Peter, B. J., Bender, R. A. \& Kustu, S. (2000). Nitrogen regulatory protein C-controlled genes of Escherichia coli: scavenging as a defense against nitrogen limitation. Proc Natl Acad Sci U S A 97, 14674-14679. 